\title{
ESTRATÉGIAS DE LUTA DAS ENFERMEIRAS DA MATERNIDADE LEILA DINIZ PARA IMPLANTAÇÃO DE UM MODELO HUMANIZADO DE ASSISTÊNCIA AO PARTO
}

\author{
Ricardo José Oliveira Moutaㄹ, Jane Márcia Progianti²
}

\footnotetext{
${ }^{1}$ Mestrando do Programa de Pós-Graduação da Faculdade de Enfermagem da Universidade do Estado do Rio de Janeiro (UERJ). Professor Substituto da Faculdade de Enfermagem da UERJ. Rio de Janeiro, Brasil. E-mail: ricardomouta@hotmail.com

${ }^{2}$ Doutora em Enfermagem. Professor Adjunto da Faculdade de Enfermagem da UERJ. Rio de Janeiro, Brasil. E-mail: jmprogi@ uol.com.br
}

RESUMO: Estudo qualitativo com abordagem histórico-social que visou identificar as estratégias de luta simbólica das enfermeiras da Maternidade Leila Diniz para a implantação de um modelo humanizado de assistência ao parto e analisar os efeitos da luta. As fontes primárias foram documentos escritos e depoimentos orais obtidos através de entrevistas semi-estruturadas com os chefes de enfermagem e enfermeiras. As etapas da análise foram: ordenação, classificação e triangulação dos dados. Para sustentação da análise utilizamos conceitos de campo, habitus, poder simbólico e capital, de Pierre Bourdieu. As estratégias encontradas foram: a busca pela titulação, a implementação do Projeto de Assistência ao Parto e Nascimento por Enfermeiros Obstetras, divulgação do capital institucionalizado no contexto científico, participação das enfermeiras no grupo de gestantes. Concluímos que as estratégias de luta desenvolvidas por estes agentes contribuíram para que as enfermeiras obstétricas conquistassem na maternidade posição hierárquica para o desenvolvimento de práticas obstétricas do modelo humanizado.

DESCRIPTORES: Parto humanizado. Enfermagem obstétrica. História da enfermagem. Enfermagem.

\section{NURSING FIGHTING STRATEGIES IN THE LEILA DINIZ MATERNITY TOWARDS THE IMPLANTATION OF A HUMANIZED MODEL FOR DELIVERY CARE}

\begin{abstract}
This a historical-social qualitative study which aimed to identify the strategies of symbolic fight of nurses in Leila Diniz Maternity to implant a humanized model of delivery assistance and analyze the effects of this fight. The primary sources were written documents and oral testimonials from semi-structure interviews with the head nurses and the nursing staff. The analysis method included the ordination, classification, and triangulation of data. For analysis, the concepts of field, habitus, symbolic power, and capital, according to Pierre Bourdieu, were used. The strategies founded were: the search for specialization, the implementation of the Delivery Assistance Project by Obstetric Nurses, the popularization of that capital/knowledge in the scientific context, and participation in the prenatal care group. We concluded the fight strategies adopted by agents contributed so that obstetric nurses would achieve a better hierarchical position in this field regarding the development of obstetric practices of the humanized model.
\end{abstract}

DESCRIPTORS: Humanizing delivery. Obstetrical nursing. Nursing history. Nursing.

\section{ESTRATEGIAS DE LUCHA DE LAS ENFERMERAS DE LA MATERNIDAD LEILA DINIZ PARA LA IMPLANTACIÓN DE UN MODELO HUMANIZADO DE ASISTENCIA AL PARTO}

RESUMEN: Es una investigación cualitativa con abordaje socio-histórico, cuyo objetivo fue identificar las estrategias de la lucha simbólica de las enfermeras de la Maternidad Leila Diniz para la aplicación de un modelo de atención al parto humanizado y analizar los efectos de esa lucha. Se usaron como fuentes primarias los documentos escritos y testimonios orales obtenidos por entrevistas semiestructuradas con los jefes de enfermería y las enfermeras. Las etapas del análisis son: ordenación, clasificación y triangulación de los datos. Se usaron los conceptos de campo, habitus, poder simbólico, y capital, según Pierre Bourdieu. Las estrategias encontradas son las siguientes: la búsqueda de especialización, la implantación del Proyecto de Asistencia al Parto por las Enfermeras Obstétricas, la divulgación de ese capital en el contexto científico, la participación de las enfermeras en el grupo de embarazadas. Se concluye que las estrategias de lucha desarrolladas por esos agentes contribuyen para que las enfermeras obstétricas conquisten una posición jerárquica para el desarrollo de las prácticas obstétricas según el modelo humanizado.

DESCRIPTORES: Parto humanizado. Enfermería obstétrica. História de la enfermería. Enfermería. 


\section{INTRODUÇÃO}

A partir dos anos 1970, nos grandes centros urbanos, os partos passaram a ser realizados pelos médicos e, nos hospitalais do Rio de Janeiro, não houve espaço profissional para a assistência ao parto normal pela enfermeira obstétrica. Tal realidade começou a se transformar quando em 1985, a Organização Mundial de Saúde (OMS) publicou o documento Tecnologia Apropriada para Partos e Nascimentos. Esse documento enfatiza os direitos da população em relação à assistência pré-natal e à informação sobre as várias tecnologias utilizadas no parto; descreve o papel das instituições de saúde em relação ao parto e ao nascimento; faz criticas ao uso desnecessário de tecnologias no parto e questiona a cientificidade das tecnologias invasivas utilizadas como rotinas no modelo biomédico. ${ }^{1}$

Nesse contexto, destacou-se dois marcos que foram determinantes para que mais tarde, acontecesse uma mudança significativa na assistência ao parto e no nascimento nas instituições municipais do Rio de Janeiro: o primeiro foi que em 1985, pela primeira vez na história da obstetrícia hospitalar, os gestores públicos municipais priorizaram a lotação em maternidades de enfermeiras concursadas e especializadas em enfermagem obstétrica. O segundo foi que em 1987, houve a inauguração do Instituto Municipal da Mulher Fernando Magalhães (IMMFM), concebido para ser um grande centro de treinamento profissional e de referência para gestações de alto risco, contemplando assim os princípios do Sistema Único de Saúde (SUS).

No IMMFM, em 1988, pela primeira vez, houve a inserção da enfermeira obstétrica na assistência ao parto hospitalar com o objetivo de reduzir os índices de asfixia perinatal. Considera-se tal fato importante na história dessas especialistas, porque acumularam capital na luta pela ocupação de espaço no campo obstétrico hospitalar da parturição o que contribuiu para serem reconhecidas como portadoras de saberes considerados fundamentais no processo de consolidação do modelo humanizado de assistência ao parto..$^{2-3}$

No inicio da década de 1990, com a Reunião Internacional da Eco 92 e com a criação da Rede Nacional pela Humanização do Parto e Nascimento (REHUNA) em 1993, as qualificações das assistências obstétrica e neonatal foram ações prioritárias da Secretaria Municipal de Saúde do Rio de Janeiro (SMS-RJ). As qualificações para a assistência obstétrica estavam em conformidade com as recomendações da Conferência Internacional para o Parto, realizada pela OMS em 1985 e asseguravam os direitos de cidadania feminina que foram reafirmados pelo governo brasileiro na Conferência do Cairo em 1994. ${ }^{3}$

Neste contexto, em 1994, foi implantado o Projeto Curicica - uma maternidade amiga da mulher e da criança, em uma área programática com comprovado déficit de leitos obstétricos. Para tanto, naquele momento, os gerentes da Superintendência da Saúde Coletiva da SMS-RJ, eram profissionais oriundas do movimento feminista e da REHUNA, as quais desenvolveram estratégias para viabilizar a primeira iniciativa de implantar o modelo de assistência humanizada ao parto e nascimento nesta cidade. Dentre as estratégias utilizadas, encontravam-se a consolidação de um convênio com o Governo Federal e a reforma física do ambiente da antiga maternidade que se localizava na esfera federal dentro do Hospital Raphael de Paula Sousa. Esta maternidade passou a ser denominada de Maternidade Leila Diniz (MLD) ${ }^{3-4}$

A criação da MLD fazia parte do processo de municipalização da assistência ao parto e a parceria com o Governo Federal facilitou a inserção dos profissionais de saúde que possuíam dois vínculos empregatícios, um da esfera municipal e um da federal, principalmente nos cargos de chefia da maternidade. ${ }^{3}$

O modelo de humanização da assistência ao parto e nascimento da MLD teve inspiração na maternidade francesa de Pithiviers, idealizada pelo médico Michel Odent. Previa em primeiro lugar, o projeto arquitetônico com ambiente agradável, acolhedor, o mais semelhante possível a uma casa, com cores relacionadas na cromoterapia, chuveiros dentro do pré-parto, banheira para hidroterapia e para parto na água e equipamentos para o parto vertical; em segundo lugar, permitia a presença do acompanhante; em terceiro, deveria respeitar o processo fisiológico do trabalho de parto, intervindo o mínimo possível, além de acolher o recém-nascido de forma a não invadir suas primeiras experiências sensoriais e motoras; e, por último, seria necessário proporcionar à mãe e ao filho o papel principal do evento, reconhecendo a autonomia da mulher, sendo os profissionais de saúde facilitadores e coadjuvantes. ${ }^{3-4}$

Superada a fase da reforma do ambiente, no ano de 1993, teve início a inserção dos profissionais de saúde nesta instituição. Nessa etapa detectouse que os gerentes da SMS-RJ tinham a intenção que os profissionais de saúde, principalmente os médicos, incorporassem os valores do modelo humanizado. Para tal, optaram como estratégia 
de treinamento as oficinas de sensibilização. Essa estratégia não foi eficiente para que a maioria dos profissionais médicos conseguisse incorporar as práticas humanizadas que distinguia o novo modelo, tanto em sua abordagem como no desenvolvimento de habilidades específicas..$^{3-4}$

No entanto, se observou que a única enfermeira que participou das oficinas e do treinamento demonstrou disposição e incorporou algumas habilidades específicas do modelo desejado, dentre elas, o incentivo ao parto de cócoras. Esta disposição manifestada pela enfermeira foi de suma importância, porque mostrou aos gerentes que essa categoria profissional era uma alternativa possível para a implantação do modelo humanizado. - $^{-5}$

Percebendo esta alternativa, os gerentes reconheceram as habilidades da enfermeira Jane Baptista Quitete Monteiro para desenvolver as práticas obstétricas humanizadas. Essa enfermeira foi então nomeada como assessora da direção da maternidade em assuntos relacionados à enfermagem obstétrica e também às práticas humanizadas de assistência ao parto, com um cargo comissionado de diretora da Divisão de Apoio Técnico, o que significou melhorar sua posição individual na estrutura institucional e, consequentemente, o poder simbólico do grupo de enfermeiras neste campo. ${ }^{5}$

O reconhecimento da enfermeira na implantação das práticas obstétricas humanizadas gerou uma luta simbólica deste grupo para ocupar o campo de atuação na assistência ao parto e nascimento. Este estudo visa identificar as estratégias de luta simbólica das enfermeiras da MLD para a implantação de um modelo humanizado de assistência ao parto e analisar os efeitos da luta simbólica. É relevante visto que contribui com a história da enfermagem no que diz respeito à participação da enfermeira obstétrica na construção da política de humanização do parto e nascimento e do campo obstétrico hospitalar.

\section{METODOLOGIA E OS CONCEITOS TEÓ- RICOS}

É um estudo qualitativo com abordagem histórico-social vinculado ao projeto de pesquisa intitulado: O processo de humanização da assistência ao parto: a participação da enfermeira na reconfiguração do campo obstétrico hospitalar, da Faculdade de Enfermagem (FENF) da Universidade do Estado do Rio de Janeiro (UERJ).

O corpus de análise deste estudo foram as fontes primárias que se constituíram de documentos escritos e depoimentos orais. Selecionamos como documentos escritos o relatório da Divisão de Apoio Técnico exercida pela a enfermeira Jane Baptista Quitete Monteiro no período de 1996 à 1998,* os documentos oficiais da SMS-RJ intitulados Diagnóstico da assistência obstétrica e neonatal na cidade do Rio de Janeiro, ${ }^{* *}$ e Projeto de Assistência ao Parto e Nascimento por Enfermeiros Obstetras (PAPNEO). ${ }^{* * *}$

O recorte inicial deste estudo foi o ano de 1996 quando a segunda gestão da chefia de enfermagem (enfermeiro neonatologista Fernando Rocha Porto) teve início em parceria com a diretora de apoio técnico (enfermeira obstétrica Jane Baptista Quitete Monteiro).

O ano de 1998 foi delimitado como recorte final, nesse ano ocorreu a exoneração da segunda gestão da chefia de enfermagem e da diretora de apoio técnico na instituição. Nesse mesmo ano, o Ministério da Saúde (MS) lançou a Autorização de Internação Hospitalar (AIH) de enfermagem, reconhecendo o parto assistido pelo profissional enfermeiro e publicou a portaria $\mathrm{N}^{\mathrm{o}} 2.815$ de 29 de maio de 1998, que limitava o pagamento das cesarianas, incentivando a assistência ao parto normal e a redução das taxas de cesarianas. ${ }^{6}$

Os depoimentos orais foram produzidos através da realização de oito entrevistas semiestruturadas no período de janeiro a março de 2008. Os sujeitos do estudo foram a diretora de apoio técnico (enfermeira obstétrica Jane Baptista Quitete Monteiro); o chefe de enfermagem (enfermeiro neonatologista Fernando Rocha Porto) ambos atuantes no período de 1996 a 1998; e as enfermeiras obstétricas da MLD (Elisabeth Silva Rocha Cavalcante, Maria Amália dos Santos Coelho, Rita de Cássia Pontes de Mattos, Sheila Cruz de Sousa dos Santos, Maria da Conceição Pereira Dutra Coutinho, Tatiana dos Santos Nascimento),

\footnotetext{
* Monteiro JBQ. Relatório da divisão de apoio técnico da Maternidade Leila Diniz, período de 6 de novembro de 1996 à 18 de maio1998.

* Secretaria Municipal de Saúde do Rio de Janeiro. Diagnóstico da assistência obstétrica e neonatal na cidade do Rio de Janeiro; 1993.

***t Monteiro JBQ, Cavalcante ESR, Mattos RCP, Santos SCS. Projeto de Assistência ao Parto e Nascimento por Enfermeiros Obstetras; 1997.
} 
que participaram da construção e da implantação do PAPNEO, no período estudado.

Para permitir um registro fiel, as entrevistas foram gravadas em MP3 (media player), após anuência do entrevistado. As mesmas duraram em média uma hora e meia. Seis entrevistas foram realizadas nos locais de trabalho das enfermeiras obstétricas, uma na residência da entrevistada e uma no Espaço Rachel Haddock Lobo da FENF/UERJ, por escolha dos depoentes. Ao introduzir as falas escolhidas no texto de análise, as mesmas foram reescritas, alterando os vícios de linguagem que dificultavam o entendimento da idéia expressa.

Os documentos escritos foram selecionados nos arquivos da Prefeitura Municipal do Rio de Janeiro, do Hospital Raphael de Paula Souza, onde se encontrava a MLD e no acervo particular do Dr. Fernando Rocha Porto (um dos agentes sociais do período estudado). Para cada documento foi criada uma ficha que explicitava o tipo de documento, autor, título, assunto, objetivos, se ele era original ou cópia, a tecnologia empregada para sua elaboração, sua origem, local e data de sua elaboração, informações pertinentes e observações.

Constituído o conjunto de dados utilizouse como método de análise as seguintes etapas propostas por Minayo: na ordenação dos dados transcreveu-se as entrevistas na íntegra com o objetivo de tornar operacional e sistematizar as idéias iniciais, direcionando o desenvolvimento das operações subseqüentes; na classificação dos dados realizou-se leituras das entrevistas transcritas e da análise documental. ${ }^{7}$

A seguir, identificou-se as estruturas relevantes dos atores sociais, as idéias centrais transmitidas pelos sujeitos e, a partir daí, organizou-se os dados em categorias e a seguir realizou-se uma triangulação, isto é, articulou-se os achados nas entrevistas com os documentos, sempre apontando para o pressuposto e os objetivos do estudo. Essa etapa foi realizada num movimento incessante entre o concreto e o abstrato, e essas idas e vindas, propiciaram que revelassem nas informações coletadas as suas especificidades. ${ }^{8}$

Para a sustentação da análise utilizou-se os conceitos de campo, habitus, capital e poder simbólico do sociólogo francês Pierre Bourdieu. Para este teórico, campo é o local onde seus ocupantes (agentes) constroem e mantêm relações de força. Para tal, desenvolvem estratégias de luta simbólicas de acordo com suas posições sociais. ${ }^{9}$

O conceito de habitus indica um conhecimento adquirido ou mesmo a disposição incorporada, quase postural, resultante de um processo de aprendizado, produto do contato com diversas estruturas sociais. ${ }^{9}$

Já o conceito de capital é definido como bens propriamente ditos, seja ele de qualquer espécie (cultural, social, político, econômico, artístico, esportivo etc.), e poder simbólico é definido como um poder invisível, o qual só pode ser exercido com a cumplicidade daqueles que não querem saber que lhe estão sujeitos ou mesmo que o exercem. ${ }^{9} \mathrm{O}$ poder simbólico que um agente exerce e a posição que ele ocupa em um determinado campo estão relacionados ao volume de seu capital incorporado ao seu habitus. Ele só é válido quando outro agente social é dotado de percepções que o legitimam e o tornam conhecido como óbvio e eficientes. ${ }^{9}$

Atendendo à Resolução No 196/96 do MS, ${ }^{10}$ que trata das normas sobre pesquisa envolvendo seres humanos, foi solicitada à direção da instituição, permissão para a realização da pesquisa. O Comitê de Ética em Pesquisa da SMS-RJ emitiu parecer favorável à realização da pesquisa conforme o protocolo $\mathrm{N}^{\circ} 190 / 07$. Todos os depoentes autorizaram a divulgação de seus nomes, assinando o Termo de Consentimento Livre e Esclarecido e a divulgação dos nomes das instituições citadas foram autorizadas pela SMS-RJ.

\section{RESULTADOS E DISCUSSÃO}

Durante a análise das fontes primárias as estratégias de luta simbólica utilizadas pelas enfermeiras para a implantação do modelo humanizado foram: a busca pela titulação de enfermeira obstétrica, a implementação do PAPNEO, a divulgação do capital institucionalizado incorporado no contexto científico e a participação das enfermeiras obstétricas no grupo de gestantes. Como efeito dessa luta simbólica se observou que as enfermeiras obstétricas ocuparam espaço na assistência ao parto da MLD e iniciaram a implementação das práticas obstétricas menos intervencionistas no parto e nascimento.

\section{A busca pela titulação de enfermeira obs- tétrica}

Para que o campo obstétrico da MLD fosse ocupado pelas enfermeiras e a assistência de enfermagem ao parto fosse implantada na perspectiva do modelo humanizado, as enfermeiras foram realizar cursos de especialização em enfermagem obstétrica (pós-graduação latu sensu), com o intuito de obter aprimoramento e poder científico. 
[...] à medida que fui buscar especialização na universidade, na UERJ, aumentou minha admiração, comecei a ver valores [...] A especialização da UERJ, eu escolhi primeiro porque eu já tinha estudado lá, conhecia os professores e já tinha ouvido falar do próprio curso de especialização, que era muito bom, que o próprio departamento materno-infantil sempre divulgava, fazia trabalho em relação à questão da área materno-infantil, eu sempre via a UERJ como, digamos, um destaque dentro dessa assistência aqui na assistência ao parto não só no Rio, mas em relação a outros estados [...] e também houve um incentivo dentro da própria instituição também para estar realizando, fazendo o curso (Enfermeira obstétrica Sheila Cruz de Sousa dos Santos).

[...] eu optei em fazer a especialização. Foi uma forma da gente garantir mais espaço pra falar das conquistas, e de lutas, de aprimorar, de ter um referencial acadêmico de ter forças, né, a gente conseguiu trazer a universidade pra dentro da maternidade (Enfermeira obstétrica Jane Baptista Quitete Monteiro).

Ao retornarem à universidade (campo científico), estas agentes buscavam o aumento do seu capital cultural institucionalizado, que é formado basicamente por títulos escolares e ainda é o produto do trabalho de instauração e de manutenção necessários para produzir e reproduzir relações duráveis e úteis capazes de proporcionar lucros materiais e simbólicos. Elas buscaram um capital no estado institucionalizado que visa ao reconhecimento por meio de certificados ou diplomas. Esse diploma confere ao seu portador um valor convencional constante e juridicamente garantido. ${ }^{11-12}$

Ao realizarem o Curso de Especialização em Enfermagem Obstétrica, estas agentes aumentaram o volume de seu capital e, consequentemente, seu poder em atuar no campo obstétrico hospitalar, pois o mesmo lhes forneceu novos conhecimentos e disposições. O título de enfermeira obstétrica autorizou legalmente as enfermeiras para o exercício de sua prática obstétrica na assistência ao parto de baixo risco, conforme o artigo oitavo, da lei $\mathrm{N}^{\circ}$ 7.498 de 25 de junho de 1986, que dispõem sobre a regulação exercício profissional. ${ }^{13}$

Neste sentido, os cursos de Especialização em Enfermagem Obstétrica, ao longo dos anos, têm contribuído para o quantitativo de especialistas na área objetivando a promoção da assistência que respeita o caráter fisiológico do processo de nascimento. ${ }^{14}$

No entanto, foi necessário o reconhecimento de sua atuação no âmbito da Secretaria Municipal de Saúde, e na própria MLD. Então, foi preciso elaborar e implantar o PAPNEO.
A implementação do Projeto de Assistência ao Parto e Nascimento por Enfermeiros Obstetras

Simultaneamente à realização do curso de especialização, algumas enfermeiras elaboraram o PAPNEO como estratégia para operacionalizar a atuação das enfermeiras obstétricas na assistência durante o trabalho de parto, parto e nascimento de maneira contínua e sistematizada no âmbito interno da maternidade.

Para tal, as enfermeiras Jane Baptista Quitete Monteiro, Elisabeth Silva Rocha Cavalcante, Rita de Cássia Pontes de Mattos e Sheila Cruz de Sousa dos Santos utilizaram neste projeto específico da enfermagem, as mesmas justificativas e objetivos do Projeto feito pelos gerentes da SMS-RJ e intitulado de Projeto Curicica - uma maternidade amiga da mulher e da criança.

Assim, o PAPNEO tinha como princípio a atuação da enfermeira pautada no estabelecimento de uma relação de confiança, solidariedade e respeito mútuo com a usuária e acompanhante. Seus objetivos se constituíram em: resgatar a prática do parto vertical, reconhecer a autonomia da gestante na condução do trabalho de parto e parto; sensibilizar e capacitar profissionais de saúde a fim de mostrar a importância do parto e do nascimento como eventos naturais; incentivar e promover a prática do aleitamento materno; e adotar os 10 passos contidos na proposta do Hospital Amigo da Criança. ${ }^{3}$

Eu e a Rita [de Cássia Pontes de Mattos], a gente fez o projeto, apresentamos para a secretaria e pro ministério, [...] foi eu, Jane [Baptista Quitete Monteiro] e a Rita [de Cássia Pontes de Mattos] [...] o projeto foi aprovado para ser implementado, eles exigiram que tivesse novas normas, que usasse as normas da maternidade, junto às normas de serviço de enfermagem. Aí a gente acrescentou o bebêtem que sair da sala de parto com a mãe e ir direto pro alojamento, que até então tava indo pro berçário (Enfermeira obstétrica Maria Amália dos Santos Coelho).

[...] pelo fato de nós termos conseguido sucesso com esse projeto, quer dizer ter de certa forma seguido a filosofia inicial da maternidade que era humanizar o nascimento, dar o direito desse bebênascer direito, então a Secretaria viu que era uma coisa viável (Enfermeira obstétrica Rita de Cássia Pontes de Mattos).

Fazendo deste modo, as enfermeiras que elaboraram o PAPNEO, usaram o valor e o poder do discurso através da competência linguística, que é inseparável da posição do locutor na estrutura 
social. ${ }^{15-16}$ Neste sentido, a estratégia de usar como referência as mesmas justificativas e objetivos do projeto Curicica abriu um canal de negociação com os gerentes da SMS-RJ para a operacionalização da atuação das enfermeiras obstétricas na humanização da assistência ao parto.

Acho que foi uma negociação, a Secretaria de Saúde tinha bons olhos para isso, então entenderam que as coisas poderiam acontecer de fato, tinha alguém fazendo e esse alguém era o enfermeiro. E o enfermeiro obstetra, de um certo modo, acabou abraçando a causa, mergulhando de cabeça [...] (Enfermeira obstétrica Jane Baptista Quitete Monteiro).

No entanto, foi preciso que este projeto, além de ter afinidades ideológicas com o modelo que se desejava implantar, apontasse sua funcionalidade para o desenvolvimento das ações das enfermeiras obstétricas, isto é, deveria mostrar como seria operacionalizado na prática. Deste modo, o PAPNEO, protegeu as enfermeiras obstétricas de serem remanejadas com o objetivo de substituir o déficit enfermeiras em outros setores.

Essa era a minha posição, não pode assumir nenhuma atividade remanejada. Tem um supervisor para isso, e o supervisor tem que se lascar para resolver os problemas da alçada dele [...] (Enfermeira obstétrica Jane Baptista Quitete Monteiro).

Essa atitude administrativa adotada pela Diretoria de Enfermagem evidencia claramente a intenção de se manter a enfermeira ocupando o espaço na assistência ao parto, de maneira contínua para desenvolver as práticas obstétricas preconizadas pelo modelo humanizado.

Deambulação, o estímulo à deambulação, mudança de posição ao banho, a imersão na piscina [...] que a gente tinha uma piscina [...] banheira, era só imersão para relaxamento mesmo, para alívio da dor. A posição vertical era uma coisa que a gente já estimulava, de praxe a gente já apresentava pra toda mulher que chegava no centro obstétrico que tinha aquela possibilidade, ou essa, ou aquela, aonde você quiser [...] na cama. O banquinho, a gente já tinha aquele banquinho meia-lua, o banquinho era apresentado a ela, o acompanhante [...] a massagem lombar, então é essas coisas que a gente já usava, já fazia parte do nosso dia-a-dia, não foi uma coisa inventada, e foi só isso, a gente não teve mais, depois que vieram outras práticas para serem aliadas (Enfermeira obstétrica Jane Baptista Quitete Monteiro).

A operacionalização do PAPNEO preconizava a inserção de novas enfermeiras obstétricas na sala de parto em escala de 24 horas com plantões fixos, acompanhando os plantões médicos.
Enfim, quem era enfermeiro obstetra estava numa escala de 24 horas, o enfermeiro do centro obstétrico chegava, assumia o plantão no centro obstétrico dane-se o que ia acontecer lá fora [...] (Enfermeira obstétrica Jane Baptista Quitete Monteiro).

Essa escala especial tinha o objetivo de amenizar os conflitos das enfermeiras obstétricas com os médicos plantonistas que não estavam habituados com essas práticas e resistiam. Simbolicamente a escala de 24 horas colocou o grupo de enfermeiras que integrava o PAPNEO mais próximo dos médicos plantonistas e estabeleceu uma distinção das mesmas em relação às outras enfermeiras da MLD.

Neste sentido Bourdieu nos afirma que todos os agentes que estão engajados num campo tem interesses fundamentais em comum, e durante a luta simbólica criam acordos entre os antagonistas sobre o que merece ser disputado. Os que participam da luta contribuem para a reprodução do jogo para produzir a crença no valor do que esta sendo disputado. ${ }^{17}$

\section{A divulgação do capital institucionalizado incorporado no contexto científico}

O desenvolvimento das práticas do modelo humanizado pelas enfermeiras obstétricas da MLD com a implantação do PAPNEO tornou-se um capital estratégico a ser divulgado como um conhecimento científico adquirido.

Aí começou o boom de ir a congressos, esse período de 96 [...] Era uma seqüência de nascimento e a gente ilustrava as coisas como vivências, relatos de experiência, a gente ilustrava com as imagens, a gente começou a escrever sobre isso, produzir, a escrever aquilo que a gente estava fazendo, estávamos vivendo, acho que era o momento da gente escrever, de ir a todos os eventos e congressos (Enfermeira obstétrica Jane Baptista Quitete Monteiro).

A gente andou em Juiz de Fora... Eu fui a Curitiba apresentar [...] ah, aí eu apresentei o projeto da maternidade, de assistência ao parto por enfermeiro, que eu me lembre a gente foi a Angra (Enfermeira obstétrica Elisabeth Silva Rocha Cavalcante).

Dentre os eventos, encontrou-se nos documentos a apresentação do estudo realizado sobre a avaliação do parto de cócoras, realizado nos dois primeiros anos de funcionamento da maternidade, apresentado em eventos científicos tanto no âmbito nacional quanto internacional.

Eu sei que a gente foi a Cuba, a gente foi num congresso em Cuba e nós apresentamos cinco trabalhos 
da maternidade [...] em Cuba [...] (Enfermeira obstétrica Elisabeth Silva Rocha Cavalcante).

As enfermeiras obstétricas da MLD foram porta-vozes autorizadas pelos gestores da SMS-RJ e pela direção da maternidade para a divulgação do modelo humanizado no âmbito nacional e internacional. Neste sentido, se salientou que no campo de lutas um grupo de agentes concede a palavra a um outro grupo de agentes porque reconhecem ser ele portador de um capital institucional de autoridade, e por isso mesmo, com crédito. ${ }^{17}$ Deste modo, ao divulgar esse capital no campo científico, as enfermeiras obstétricas contribuíram para fortalecer as bases científicas do modelo humanizado, que naquele momento, concorria com o modelo tecnocrático atitude fundamental para a sua sustentação. Ao mesmo tempo, divulgando suas habilidades práticas, também estavam fortalecendo sua posição nesse campo. ${ }^{18-20}$

\section{A participação das enfermeiras obstétricas no grupo de gestantes}

Ao longo dos tempos foi crescente a medicalização da sociedade brasileira e o parto constitui um marco neste processo, caracterizando-se como uma forma especial de medicalização. ${ }^{19}$ Durante esse processo as mulheres absorveram, dentre outros valores, que o parto deveria acontecer no âmbito hospitalar e ser realizado por médicos, o que aumentou em muito as cesarianas no Brasil. Desta maneira a própria superintendente de saúde coletiva da SMS-RJ reconheceu as causas da escolha da mulher pela cesariana.

"A escolha do parto cesáreo por parte da mulher está associada ao medo da dor e a uma cultura intervencionista e onipotente que abomina e deseja controlar aquilo que é instintivo e natural, e por isso mesmo é interpretado como antigo e ultrapassado. Além do medo da dor, a mulher é, também, muitas vezes, induzida pela atitude do médico que não lhe informa sobre os riscos e contra-indicações deste procedimento cirúrgico $[\ldots]^{\prime \prime} .21: 03$

Contra essa cultura as enfermeiras obstétricas precisaram mostrar para as gestantes como era a sua atuação na maternidade e que lá existia também um profissional não médico que assistia aos partos normais. Para obter o apoio das mulheres, a opção possível foi introduzir a sua participação nos grupos de gestantes do Pré-Natal, que era realizado no Hospital Raphael de Paula Sousa, situado ao lado da própria MLD.
Outra estratégia também utilizada foi o grupo de gestantes [...] que era no [Hospital] Raphael [de Paula Souza] [...] os enfermeiros da maternidade conversavam com as gestantes, então falavam de parto vertical, eu ia e falava sobre criança, sobre aleitamento, e isso também já era uma forma estratégica da gente se mostrar (Enfermeiro neonatologista Fernando Rocha Porto).

Ao usar essa estratégia, as enfermeiras obstétricas buscavam visibilidade e difundir o modelo entre as futuras parturientes. Utilizaram a educação em saúde para oferecer subsídios às mulheres na tentativa de influenciar novos hábitos e condutas de saúde nas mulheres. ${ }^{22-23}$

\section{Os efeitos das estratégias de luta simbólica das enfermeiras obstétricas da Maternidade Leila Diniz}

Na implantação do modelo humanizado de assistência ao parto na MLD, considerou-se como os efeitos das estratégias de luta as contribuições e as perdas do grupo pesquisado.

Se constatou que essa luta contribuiu para o início do desenvolvimento das práticas obstétricas humanizadas na assistência ao parto da MLD.

A gente usava a água, a gente já usava a água, a gente já tinha a banheira, nós não usávamos como parto, mais a gente usava como relaxamento, a gente já usava a água como relaxamento lá, a deambulação, foi uma conquista da gente, a inserção do suco no pré parto porque era uma coisa bem difícil né. A gente chegou e já existia a dieta zero e com o tempo a gente começou a vencer isso, inserindo o suco no pré parto quer dizer [...] deambulação, a gente tinha um jardinzinho, agente tinha nosso solário, que a gente levava as parturientes para deambular lá no solário e aí depois veio a bola, enfim cada. [...] fizemos o parto de cócoras, então foi uma evolução a medida que a gente ia aprendendo novas tecnologias a gente ia implementando [...] (Enfermeira obstétrica Tatiana dos Santos Nascimento).

Nós que no inicio, utilizamos a bola. Aí começamos com a bola, com aquele cavalinho. A gente não tinha muita coisa. A bola, o banquinho e aquela coisinha de massagem. A gente começou com pouquinha coisa. Deambular, coisas assim bem simples, por que a gente ainda não tinha aquela salinha. Depois nós montamos uma salinha [...] uma salinha de relaxamento. (Enfermeira obstétrica Maria da Conceição Pereira Dutra Coutinho).

A implementação dessas práticas, no contexto estudado (1996-1998), significou para as enfermeiras uma importante conquista de espaço 
e posição no campo obstétrico hospitalar, tanto que após a implantação do PAPNEO na MLD, no relatório da Divisão de Apoio Técnico constou que o percentual de partos assistidos pelas enfermeiras obstétricas subiu de 7,4\% do total de partos da maternidade para $18,2 \%$. No ano de 1997, foram totalizados 491 partos realizados pelas enfermeiras obstétricas, sendo que 6,3\% foram realizados na posição vertical.

A ocupação desse espaço pela enfermeira e a sua atuação na MLD, contribuiu também para reforçar os gerentes da SMS-RJ que em 1998, seguindo seu projeto de modificar a assistência ao parto medicalizado, treinou e inseriu enfermeiras obstétricas nas maternidades municipais Unidade Integrada de Saúde Herculano Pinheiro e Hospital Maternidade Alexander Fleming.

[...] eu podia optar, ou eu ia para qualquer unidade de saúde da área, da AP [Área Programática] 4, qualquer unidade de saúde, ou eu poderia ir para a Secretaria de Saúde, ou seja, foi oferecido,, a possibilidade de eu ir para o programa da mulher do PAISM no nível central. E aí eu fui [...] fiquei um ano mais ou menos trabalhando a gerência do programa da mulher, treinando, capacitando enfermeiras que iriam reproduzir esse projeto para implantar a mesma atuação na Alexandre Fleming e na Herculano Pinheiro, então nós fizemos a capacitação teórica (Enfermeira obstétrica Jane Baptista Quitete Monteiro).

As perdas do grupo pesquisado foram geradas porque suas estratégias não foram eficientes para superar as resistências do grupo de médicos plantonistas, que era opositor ao modelo e que não aceitava agir conforme os princípios dos gerentes e das enfermeiras obstétricas. Esse grupo opositor exigiu do diretor da maternidade que as lideranças da enfermagem fossem destituídas de seus cargos.

A equipe médica disse que se nós não saíssemos os médicos pediriam demissão por que chegou num ponto de que realmente a maternidade era gerenciada pelos enfermeiros, por que na verdade estavam em todas as instâncias e atendendo diretamente ao cliente. A gente não era só gerente, a gente intervinha em todo processo (Enfermeira obstétrica Elizabeth Silva Rocha Cavalcante).

Ao agir assim, esse grupo de médicos rompeu o fluxo do poder simbólico porque usou o embate direto como estratégia para impor sua visão e assim, subverteu as fundações da produção e da reprodução dos princípios e das práticas do modelo humanizado. Ao entrar neste jogo com conflitos abertos, as lideranças do grupo de enfermeiras obstétricas perderam apoio dentro da maternidade e a pressão política dos médicos fez com que o diretor da MLD, em 1998 exonerasse a enfermeira diretora de apoio técnico e as chefias de enfermagem.

Para o grupo exonerado, tal atitude ocorreu devido aos resultados de seu trabalho que lhe conferia prestígio político e visibilidade no campo científico.

E aí a gente começou a ter resultado [...] o número de trabalhos produzidos era grande [...] eu nunca escrevi tanto na minha vida quanto na Leila Diniz, né, nunca passei tanto escrevendo quanto na Leila Diniz, e olha que eu era a que participava menos [...] que eu ia menos para os eventos [...] mas aí aconteceu à exoneração (Enfermeira Obstétrica Elisabeth Silva Rocha Cavalcante).

No entanto, essas exonerações aconteceram num momento crucial no qual a SMS/RJ estava disseminando para outras maternidades do município o modelo humanizado de assistência ao parto com a participação de enfermeiras obstétricas, portanto, não deveria arriscar perder esse objetivo mais amplo em detrimento dos conflitos restritos à MLD.

No dia seguinte o diretor falou: "vocês não vão me deixar outra opção", a não ser exonerá-los [...] é a instituição [...] eu vou exonerar vocês. Ficamos arrasados naquele dia emocionalmente, me lembro [...] (Enfermeiro Neonatologista Fernando Rocha Porto).

Por outro lado, a exoneração destes agentes pelo diretor significou impor limites de poder e fortaleceu o grupo médico opositor que historicamente domina o espaço hospitalar. Assim, a exoneração também foi num instrumento de legitimação da dominação, no caso a médica, que mostrou sua força no campo. ${ }^{17}$

Mas, no intuito de manter a aliança com as enfermeiras, os gerentes daSMS/RJ, reconheceram o poder do grupo exonerado e os mantiveram em posição estratégica de agentes disseminadores do modelo humanizado para toda a rede municipal.

[...] a gente foi pra secretaria, e aí nós é que implantamos o projeto de assistência ao parto humanizado na AP [Área Programática] 3.3[...] (Enfermeira obstétrica Elisabeth Silva Rocha Cavalcante).

Tal atitude dava oportunidade ao grupo exonerado de continuar aliado e de continuar utilizando a força de seu capital na luta pela implantação das práticas obstétricas humanizadas neste campo. Tanto que, em agosto de 1998, logo após sua saída da maternidade, a enfermeira obs- 
tétrica Jane Baptista Quitete Monteiro, chegou a ser reconhecida nacionalmente quando o MS, a Secretaria Municipal de Saúde do Ceará e a Agência de Cooperação Internacional do Japão, colocou sua foto prestando assistência a uma parturiente, no cartaz da - Conferência Nacional sobre Organização de Serviços para Maternidade Segura à Luz da Humanização.

A Jane [Baptista Quitete Monteiro] foi reconhecida nacionalmente pela JICA, por tal cartaz, até aloum tempo atrás no último SENPE [2007], que foi em Florianópolis. Ela foi conhecer o Hospital Universitário de Florianópolis que eu já conhecia porque na época da [maternidade] Leila Diniz outros enfermeiros visitavam a [maternidade] Leila Diniz [...] Então a Jane [Baptista Quitete Monteiro] quando chega em Florianópolis para o último SENPE [2007], encontra o cartaz num quadro, ela estava com a mãe, ficou emocionada, é conhecida nacionalmente, quiçá internacionalmente (Enfermeiro neonatologista Fernando Rocha Porto).

A atuação da enfermeira na MLD continuou sob a liderança da enfermeira obstétrica Leila Gomes de Azevedo que deu continuidade ao PAPNEO e é hoje diretora da Casa de Parto David Capistrano Filho/SMS-RJ, a única existente na cidade do Rio de Janeiro até o momento.

\section{CONCLUSÃO}

Na cidade do Rio de Janeiro, em 1994, com a criação da MLD iniciou-se a implantação da proposta de humanização da assistência ao parto. Nessa instituição foram lotados profissionais de saúde para desenvolverem práticas assistenciais que contemplassem a mulher como protagonista de seu parto. Nesse processo participaram ativamente desenvolvendo estratégias de luta simbólica.

A busca pela titulação de enfermeira obstétrica foi uma estratégia eficiente porque agregou ao diploma de enfermeira um capital institucionalizado em forma de certificado, que em nosso país legitima a prática da enfermeira no parto e nascimento. Essa especialidade cursada em uma universidade, também aumentou o volume de seu capital científico, o que lhe conferiu mais poder no campo obstétrico hospitalar, principalmente, em relação ao grupo médico que estava no topo da hierarquia do mesmo. Tal fato proporcionou à enfermeira melhores condições de luta.

Com o objetivo de ocuparem espaço na assistência ao parto, as enfermeiras elaboraram o PAPNEO, onde simbolicamente demonstraram que suas concepções estavam afinadas com o projeto da MLD, além de proporem uma atuação de enfermagem obstétrica sistematizada para implementação do modelo humanizado desejado.

Ao serem reconhecidas pelos gerentes da SMS-RJ, as enfermeiras obstétricas implementaram as práticas obstétricas, o que causou muitos conflitos com a equipe de médicos plantonistas. Mesmo assim, sua prática era um conhecimento a ser divulgado no campo científico com o objetivo de obter o máximo de reconhecimento social. Desse modo, a divulgação do capital institucionalizado incorporado pela enfermeira passou a ser uma estratégia de luta simbólica porque consolidava as bases científicas do modelo humanizado e dava a visibilidade necessária para mantê-la neste campo diante das adversidades do grupo médico.

No entanto, para que as enfermeiras obstétricas se consolidassem nesse espaço, faltava o apoio das mulheres usuárias dos serviços da MLD. Foi então que elas começaram a participar no grupo de gestantes durante o pré-natal. Essa estratégia simbolicamente significou uma luta por visibilidade profissional e reconhecimento social, mas também contribuiu para divulgar o novo modelo para a clientela.

Se entendeu que as estratégias de luta utilizadas pelo grupo de enfermeiras pesquisadas foram eficientes para que as enfermeiras melhorassem sua posição e poder na MLD o que resultou na implantação do modelo humanizado de assistência ao parto nessa instituição.

No entanto, essas estratégias não foram eficientes para impor ao grupo médico plantonista esta visão de mundo, o que resultou como efeito a exoneração das lideranças da enfermagem da MLD no período estudado. Contudo, se constatou que a atuação das enfermeiras obstétricas foi garantida pela direção médica da MLD e que as lideranças exoneradas continuaram seu trabalho em outro espaço, treinando enfermeiras para o modelo humanizado de assistência ao parto que foi expandido em outras maternidades da SMS/ RJ a partir de 1998.

\section{REFERÊNCIAS}

1. World Health Organization. Appropriate technology for birth. Lancet. 1985 Aug 24; 2(8452):452-76

2. Vargens OMC, Progianti JM. O processo de desmedicalização da assistência à mulher no ensino da enfermagem. Rev Esc Enferm USP 2004; 38(1):46-50. 
3. Mouta RJO. A reconfiguração do espaço social da Maternidade Leila Diniz: a luta das enfermeiras obstétricas pela implantação do modelo humanizado de assistência ao parto [dissertação]. Rio de Janeiro (RJ): Universidade do Estado do Rio de Janeiro. Faculdade de Enfermagem; 2009.

4. Lima KMR. Maternidade Leila Diniz (1994-1996): nascimento de um novo profissional de saúde? [dissertação] Rio de Janeiro (RJ): Fundação Instituto Oswaldo Cruz. Instituto Fernandes Figueiras; 1997.

5. Progianti JM, Mouta RJO. A enfermeira obstétrica: agente estratégico na implantação de práticas do modelo humanizado em maternidades. Rev. Enferm. UERJ. 2009 Abr-Jun; 17(2):165-9.

6. Ministério da Saúde (BR). Portaria № 2815 de 29 de maio de 1998. Trata da inclusão na tabela do Sistema de Informações Hospitalares do Sistema Único de Saúde (SIH/SUS) de procedimentos e valores para assistência ao parto sem distócia por enfermeiro. Diário Oficial da República Federativa do Brasil, 2 Jun 1998. Seção 1.

7. Minayo MCS. O desafio do conhecimento: pesquisa qualitativa em saúde. $9^{a}$ ed. São Paulo (SP): HUCITEC; 2006.

8. Driessnack M, Sousa VD, Mendes IAC. Revisão dos desenhos de pesquisa relevantes para enfermagem: parte 3: métodos mistos e múltiplos. Rev Latino-am Enferm [online]. 2007 Set-Out [acesso 2007 Mar 15]; 15(5):1046-9. Disponível em: http:/ / www.scielo.br/ pdf/rlae/v15n5/pt_v15n5a24.pdf

9. Bourdieu P. O poder simbólico. $9^{\mathrm{a}}$ ed. Rio de Janeiro (RJ): Bertrand Brasil; 2006.

10. Ministério da Saúde (BR), Conselho Nacional de Saúde. Resolução No 196 de 10 de outubro de 1996: diretrizes e normas regulamentadoras de pesquisa envolvendo seres humanos. Brasília (DF): MS; 1996.

11. Bourdieu P. Escritos de educação. $8^{\mathrm{a}}$ ed. Petrópolis (RJ): Vozes, 1998.

12. Bourdieu P. Os usos sociais da ciência - por uma sociologia clínica do campo científico. São Paulo (SP): UNESP, 2004.
13. Brasil. Lei $\mathrm{N}^{\circ} 7.498$, de 25 de junho de 1986. Dispõe sobre a regulamentação do exercício da Enfermagem e dá outras providências. Diário Oficial da República Federativa do Brasil, 26 Jun 1986 [acesso 2007 Mar 15]. Seção 1. Disponível em: http://www.portalcofen.gov.br/2007/materias. asp?ArticleID=22\&sectionID=35.

14. Monticelli M, Brüggemann OM, Santos EKA, Oliveira ME, Zampieri MFM, Gregório URP. Especialização em enfermagem obstétrica: percepções de egressas quanto ao exercício profissional e satisfação na especialidade. Texto Contexto Enferm. 2008 Jul-Set; 17(3):482-91.

15. Bourdieu P. A economia das trocas simbólicas. São Paulo (SP): Perspectiva; 1999.

16. Ortiz R, organizador. Bourdieu: sociologia. v. 39. São Paulo (SP): Ática; 1983. p. 156-83.

17. Bourdieu P. Questões de sociologia. Rio de Janeiro (RJ): Marco Zero; 1983.

18. Davis-Floyd R. The technocratic, humanistic, and holistic paradigms of childbirth. Int J Gynaecol Obstet. 2001 Nov; 75(Suppl 1):5-23.

19. Macedo PO, Progianti JM, Vargens OMC, Santos VL, Silva CA. Percepção da dor pela Mulher: a influência do ambiente de pré-parto. Rev Enferm UERJ. 2005 Set-Dez 13(3):306-12.

20. Vargens OMC, Progianti JM, Silveira ACF. O significado de desmedicalização de assistência ao parto no hospital: análise da concepção das enfermeiras obstétricas. Rev Esc Enferm USP. 2008; 42(2):339-46.

21. Boaretto MC, Bursztyn I. O direito de nascer direito. O Globo, 1995 Dez 15:3.

22. Progianti JM, Costa RF. A negociação do cuidado de enfermagem obstétrica através das práticas educativas na casa de parto. Esc Anna Nery Rev Enferm. 2008 Out-Dez; 12(4):789-92.

23. Boehs AE, Monticelli M, Wosny AM, Heidemann IBS, Grisotti M. A interface necessária entre enfermagem, educação em saúde e o conceito de cultura. Texto Contexto Enferm. 2007 Ab-Jun; 16(2):307-14. 